\title{
Rapid Hemodynamic Deterioration and Death due to Acute Severe Refractory Septic Shock
}

\author{
Abhijeet Dhoble ${ }^{\mathrm{a}, \mathrm{b}}$, Won Chung ${ }^{\mathrm{a}}$
}

\begin{abstract}
Despite emergence of early goal directed therapy, septic shock still carries a high mortality. Gram negative septicemia is notorious for rapid deterioration due to endotoxin release. Multi-organ damage due to septic shock carries poor prognosis, and such patients should be managed aggressively with multidisciplinary approach. We present a fatal case of a patient with gram negative septicemia who rapidly deteriorated, and died due to acute refractory severe septic shock. This patient probably developed urosepsis secondary to severe urinary tract infection. He also had infiltrates on chest radiograph. He expired within fifteen hours of presenting to the emergency department. This case emphasizes the importance of early recognition and management of septic shock. Early goal directed therapy has shown to improve mortality. Broad spectrum antibiotics should be started within one hour depending on local immunity of organisms. This case also highlights the fact that despite optimized treatment, this entity has very high mortality rates.
\end{abstract}

Keywords: Hemodynamic deterioration; Refractory Septic Shock; Gram negative septicemia

\section{Introduction}

Sepsis is a clinical syndrome which is characterized by severe infection leading to systemic inflammation and widespread cellular injury [1]. Similar systemic response also occurs in the absence of an infection. This entity is different

Manuscript accepted for publication May 4, 2009.

${ }^{a}$ Department of Internal Medicine, Michigan State University, East Lansing, Michigan, USA

${ }^{\mathrm{b} C}$ Corresponding autor: Department of Internal Medicine, B 308 Clinical Center, Michigan State University, East Lansing, MI, USA, 48824-1313.

E-mail: Abhijeet.Dhoble@ht.msu.edu

doi:10.4021/jocmr2009.04.1238 from culture negative sepsis syndrome, in which case there is an evidence or suspicion of infection, but blood or body fluid cultures are negative [2,3]. In fact, blood cultures are negative in 30 to 80 percent of patients with sepsis depending on the severity of syndrome [3].

Bloodstream infection is associated with high mortality rates. When bacteremia is associated with severe septic shock, gram negative and gram positive bacteria have comparable outcomes [4]. Dysregulation of anti and pro-inflammatory modulators is currently believed to be the center of pathogenesis of sepsis syndrome. Excessive spill of proinflammatory cytokines results in vasodilatation, increased endothelial permeability, leukocyte accumulation and neutrophils degranulation; leading to chain of events ensuing extensive tissue injury [5]. Cellular injury also plays an important role in the pathogenesis of sepsis through local hypoxia, apoptosis of injured cells, and direct cytotoxic effects [6]. Combination of excessive inflammation and cellular injury gives rise to full blown picture of sepsis syndrome (Fig. 1).

Gram negative septicemia is notorious for rapid deterioration due to endotoxin release [7]. Multi-organ damage due to septic shock carries poor prognosis, and such patients should be managed aggressively with multidisciplinary approach [8]. In spite of optimum treatment, refractory septic shock has very high mortality rates up to $50 \%$ [9]. Early goal directed therapy (EGDT) has shown to improve short and long term survival in these patients by $20 \%$. EGDT is the mainstay of therapy while treating these patients [10]. We present a not very uncommon case of acute refractory gram negative septic shock, which rapidly deteriorated and died within 15 hours of his initial presentation to the emergency department.

\section{Case report}

A 65-years-old male patient presented to emergency department with complaints of progressive dyspnea, dysuria, and change in mental status in last six hours. The patient had a history of hypertension, type-2 diabetes mellitus, coronary artery disease, hypertriglyceridemia, peripheral vascular disease, chronic pancreatitis, gastroesophageal reflux disease, 


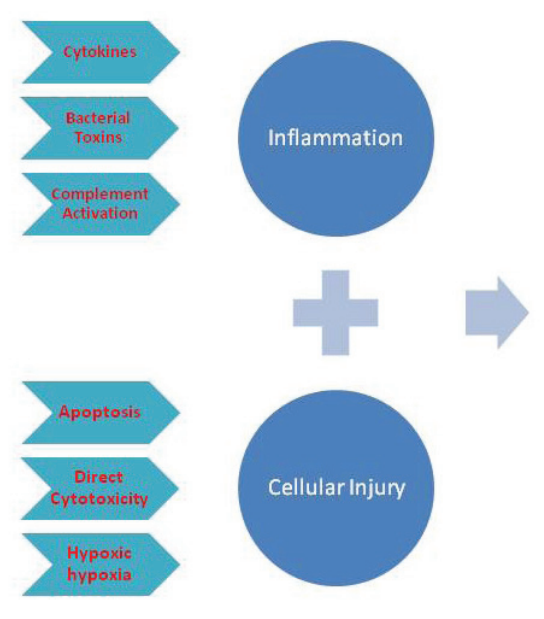

Figure 1. Pathogenesis of sepsis.

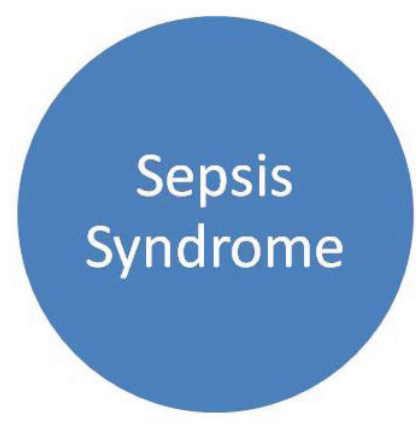

code blue was called. Cardio-pulmonary resuscitation was performed as per standard protocol for 15 minutes, and patient came back to sinus rhythm. After the code, patient was hypotensive and required three vasopressors including epinephrine, norepinephrine and dopamine to maintain systolic BP more than 90 . Oxygen saturation was $90 \%$ on $100 \% \mathrm{FiO}_{2}$. After one hour, patient again went into cardiac asystole, then ventricular fibrillation, and then pulseless electrical activity. Successful resuscitation was done for 15 minutes. After this second code, the systolic BP was in 80 s, and IV phenylephrine was added. Hear rate was 146 beats per minute, and oxygen saturation $88 \%$ on $100 \% \mathrm{FiO}_{2}$. The laboratory results showed lactate level of $12.1 \mathrm{mmol} / \mathrm{L}$; transaminase in 1000's and blood urea nitrogen and creatinine of $53 \mathrm{mg} /$ $\mathrm{dl}$ and $4.9 \mathrm{mg} / \mathrm{dl}$ respectively. Serum troponin level was 2.92 $\mathrm{ng} / \mathrm{ml}$ (normal $\leq 0.04 \mathrm{ng} / \mathrm{ml}$ ). Arterial blood gas $(\mathrm{ABG})$ revealed worsening metabolic acidosis.

An emergent two-dimensional echocardiogram was obtained and revealed normal left and right ventricular function. His left ventricular ejection fraction was found to be $50 \%$, and there was no pericardial effusion, or right ventricular strain. Patient was started on IV hydrocortisone, and anidulafungin was added to cover for fungal pathogens. A decision was also made to start patient on activated protein $\mathrm{C}$ infusion considering high risk of death. In addition, bicarbonate drip was also started.

Twelve hours after his admission to this hospital, patient started showing signs of anoxic brain injury. At that time, he was on maximum doses of five vasopressors, but was still hypotensive and tachycardic. The oxygen saturation decreased to $88 \%$ on $100 \%$ of $\mathrm{FiO}_{2}$. ABG at that time is shown in table 2. Family meeting was called, and they requested for withdrawal of care. Thirty minutes later, care was withdrawn and 
Table 1. Initial laboratory values

\begin{tabular}{|c|c|c|}
\hline Test & Value & Value range \\
\hline Sodium & $136 \mathrm{meq} / \mathrm{l}$ & $135-145$ \\
\hline Potassium & $3.6 \mathrm{meq} / 1$ & $3.5-4.9$ \\
\hline Chloride & $112 \mathrm{meq} / 1$ & $96-110$ \\
\hline $\mathrm{CO}_{2}$ & $11 \mathrm{mmol} / 1$ & $20-30$ \\
\hline $\begin{array}{l}\text { Blood urea } \\
\text { nitrogen }\end{array}$ & $28 \mathrm{mg} / \mathrm{dl}$ & $6.0-23.0$ \\
\hline Creatnine & $1.7 \mathrm{mg} / \mathrm{dl}$ & $0.6-1.4$ \\
\hline Total protein & $6.4 \mathrm{~g} / \mathrm{dl}$ & $6.0-8.0$ \\
\hline Albumin & $3.7 \mathrm{~g} / \mathrm{dl}$ & $3.6-5.0$ \\
\hline Magnesium & $1.4 \mathrm{meq} / 1$ & $1.3-2.2$ \\
\hline Phosphorus & $3.2 \mathrm{mg} / \mathrm{dl}$ & $2.5-4.5$ \\
\hline Calcium & $8.3 \mathrm{mg} / \mathrm{dl}$ & $8.0-10.5$ \\
\hline White blood count & $13,900 / \mathrm{mm}^{3}$ & $4-12$ \\
\hline Hemoglobin & $13.6 \mathrm{~g} / \mathrm{dl}$ & $12.6-16.5$ \\
\hline Platelet count & $119000 / \mathrm{mm}^{3}$ & $150-400$ \\
\hline
\end{tabular}

patient expired within 10 minutes of extubation and stopping IV medications. Family refused autopsy. The next day, two out of four blood cultures were positive for Escherichia coli.

\section{Discussion}

There are approximately 750,000 cases of sepsis diagnosed in the United States annually [11]. It occurs in approximately two percent of hospitalized patients and up to 75 percent of intensive care unit patients [12-15]. Hospital mortality rate for sepsis patients ranges from 20 to 50 percent [12]. Despite an 8 percent per year increase in the incidence of sepsis, mortality rate have declined over the past 20 years [12-14]. Among patients with sepsis, the severity of disease appears to be increasing. In one large retrospective analysis, the proportion of patients with severe sepsis increased from 26 to 44 percent over a decade $[13,14]$. Despite this, hospital case-fatality rates declined dramatically [15]. The trends of
Table 2. Arterial blood gas analysis

\begin{tabular}{|c|c|c|c|}
\hline ABG & $\begin{array}{l}\text { At } \\
\text { presentation }\end{array}$ & $\begin{array}{l}\text { After } \\
12 \text { hours }\end{array}$ & $\begin{array}{l}\text { Normal } \\
\text { values }\end{array}$ \\
\hline $\mathrm{pH}$ & 7.26 & 6.9 & $\begin{array}{l}7.35- \\
7.45\end{array}$ \\
\hline $\begin{array}{l}\mathrm{PaO}_{2} \\
(\mathrm{~mm} \mathrm{Hg})\end{array}$ & 68 & 90 & $80-95$ \\
\hline $\begin{array}{l}\mathrm{PaCO}_{2} \\
(\mathrm{~mm} \mathrm{Hg})\end{array}$ & 25 & 37 & $35-45$ \\
\hline $\begin{array}{l}\mathrm{HCO}_{3}^{-} \\
(\mathrm{mEq} / \mathrm{L})\end{array}$ & 10.6 & 6 & $22-26$ \\
\hline $\begin{array}{l}\mathrm{O}_{2} \\
\text { Saturation }\end{array}$ & $85 \%$ & $84 \%$ & $95-99 \%$ \\
\hline $\mathrm{FiO}_{2}$ & $100 \%$ & $100 \%$ & \\
\hline
\end{tabular}

increasing incidence and improved survival have also been observed for septic shock [12-15]. Mortality rates increase stepwise according to disease severity [12-14].

The contribution of various infectious organisms to the burden of disease has changed over time. Gram negative bacilli were the predominant organisms associated with nosocomial bacteremia in the US prior to the 1980s [16]. Gram positive aerobes now outnumber Gram negative organisms $[11,17]$, especially the emergence of methicillin resistant staphylococcus aureus. Although the percentage of gram negative bacillary bacteremia has decreased, these cause serious multidrug resistance problems increasing mortality rate [18], and is usually associated with at least one comorbid condition [19]. In 2003, gram-negative bacilli were respon-

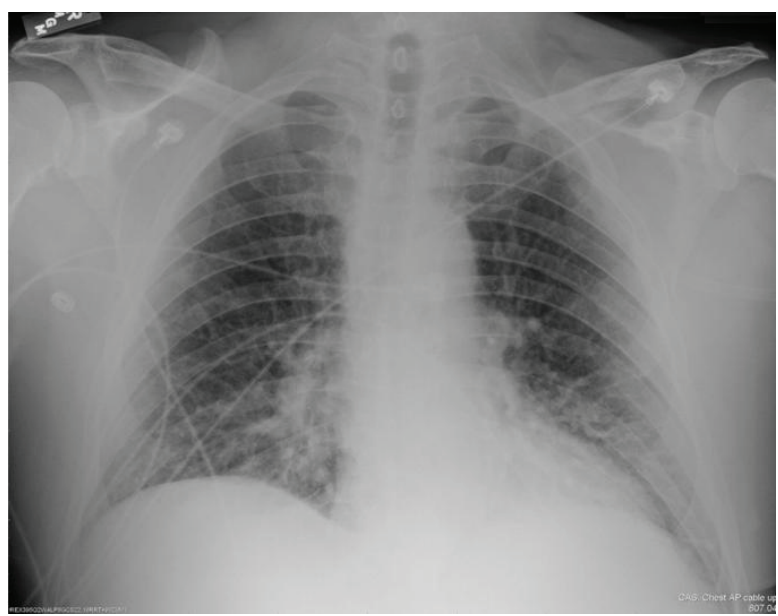

Figure 2. Chest radiograph at presentation. 
Table 3. Urine analysis

\begin{tabular}{lll}
\hline Test & Findings & Normal values \\
\hline White blood count & $>100 / \mathrm{hpf}$ & $0-2 / \mathrm{hpf}$ \\
Red blood count & $1 / \mathrm{hpf}$ & $0-2 / \mathrm{hpf}$ \\
Bacteria & & \\
& many & none \\
Leukocyte esterase & Positive (large) & Negative \\
& & \\
Nitrite & Positive (large) & Negative \\
\hline
\end{tabular}

sible for 24 percent of nosocomial bacteremias in ICUs [16]. American college of chest physicians and society of critical care medicine have proposed definitions of sepsis and related syndromes (Fig. 3); and these are widely used while stratifying the risks for hospitalized patients [20]. These definitions of systemic inflammatory response syndrome (SIRS), sepsis, severe sepsis, and septic shock are based on clinical experience and the correlation of infection progression with appropriate physiologic responses.

EGDT has shown to increase survival by $20 \%$ [10], and should be initiated as soon as the diagnosis is suspected. This include invasive hemodynamic monitoring with the aim of maintaining: central venous pressure (CVP) between 8 and $12 \mathrm{~mm} \mathrm{Hg}$, mean arterial pressure ${ }^{3} 65 \mathrm{~mm} \mathrm{Hg}$, urine output ${ }^{3} 0.5 \mathrm{~mL} / \mathrm{kg} / \mathrm{hr}$, and central venous or mixed venous oxygen $\left(\mathrm{SvO}_{2}\right)$ saturation ${ }^{3} 70 \%$. If the $\mathrm{SvO}_{2}$ is less than $70 \%$ after maintain CVP of 8-12 mm Hg, infusion of packed red blood cells is indicated to maintain hematocrit of at least $30 \%$. Dobutamine infusion is also indicated if cardiac output is compromised $[10,20]$. Appropriate cultures should be obtained before starting antibiotics.

Intravenous antibiotics should be started as early as possible and always within the first hour of recognizing severe sepsis and septic shock [20]. The site of infection and responsible microorganisms are usually not known initially in a patient with sepsis. Antibiotic treatment must be guided by the patient's susceptibility group and local knowledge of bacterial resistance [21]. Intravenous broad spectrum antibiotics directed against both gram positive and gram negative bacteria should be administered immediately after appropriate cultures have been obtained. Few guidelines exist for the initial selection of empiric antibiotics. If pseudomonas is an unlikely pathogen, combination of vancomycin with either the third or fourth generation cephalosporin, or beta-lactam/

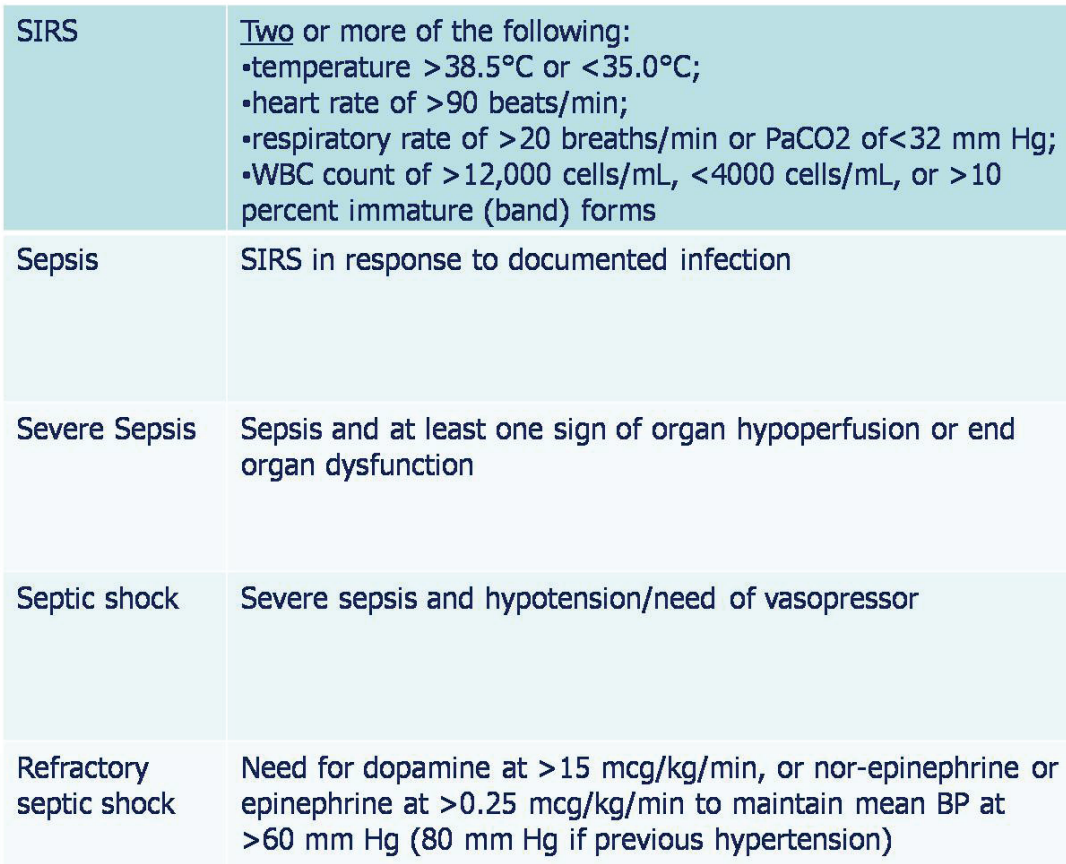

Figure 3. Definitions used to describe the condition of septic patients (Adapted from American college of chest physicians and society of critical care medicine's surviving sepsis campaign published in 2008). 
beta-lactamase inhibitor, or carbapenem is an excellent initial choice. If pseudomonas is a possible pathogen, combination of vancomycin and two antipseudomonal agents should be considered. Antifungal agent may be considered initially if risk factors for fungal infection are present, or within 48 hours if no improvement occurs [21]. Antimicrobial regimen should be reassessed in 48-72 hours on the basis of microbiological and clinical data [22]. Antibiotics should be stopped if the cause is found to be non-infectious.

Intravenous hydrocortisone is indicated for adult septic shock when hypotension responds poorly to adequate fluid resuscitation and vasopressors. Hydrocortisone dose should be $\leq 300 \mathrm{mg} /$ day. Steroids are not recommended to treat sepsis in the absence of shock unless the patient's endocrine or corticosteroid history warrants it [23]. Recombinant human activated protein $\mathrm{C}$ should be considered in adult patients with sepsis-induced organ dysfunction with clinical assessment of high risk of death and if there are no contraindications [24].

Our case emphasizes the importance of early recognition and management of septic shock. Gram negative septicemia is notorious for rapid deterioration due to endotoxin release. Multi-organ damage due to septic shock carries poor prognosis, and such patients should be managed aggressively with multidisciplinary approach. This case also highlights the fact that despite optimized treatment, this entity has very high mortality rates as shown in the previous studies. Nonetheless, early recognition, EGDT, and initiation of intravenous antibiotics are key components in treating patients with sepsis and septic shock.

\section{Acknowledgements}

The authors do not have any competing interests.

\section{References}

1. Pinsky MR, Matuschak GM. Multiple organ failure: Failure of host defense homeostasis. Crit Care Clin 1989;5:199.

2. Bone RC. Immunologic dissonance: A continuing evolution in our understanding of the systemic inflammatory response syndrome (SIRS) and the multiple organ dysfunction syndrome (MODS). Ann Intern Med 1996; 125:680.

3. Brun-Buisson C, Doyon F, Carlet J. Bacteremia and severe sepsis in adults: A multicenter prospective survey in ICUs and wards of 24 hospitals. Am J Respir Crit Care Med 1996; 154:617.

4. Miller PJ, Wenzel RP. Etiologic organisms as independent predictors of death and morbidity associated with bloodstream infections. J Infect Dis 1987; 156:471.

5. Pruitt JH, Copeland EM, Moldawer LL. Interleukin-1 and interleukin-1 antagonism in sepsis, systemic inflammatory response syndrome, and septic shock. Shock 1995; 3:235.

6. Bone RC. The pathogenesis of sepsis. Ann Intern Med 1991;115:457.

7. Movat HZ, Cybulsky MI, Colditz IG, Chan MK, Dinarello CA. Acute inflammation in gram-negative infection: Endotoxin, interleukin-1, tumor necrosis factor, and neutrophils. Fed Proc 1987;46:97.

8. Zeni F, Freeman B, Natanson C. Anti-inflammatory therapies to treat sepsis and septic shock: A reassessment. Crit Care Med 1997;25:1095.

9. Rangel-Frausto MS, Pittet D, Costigan M, Hwang T, Davis CS, Wenzel RP. The natural history of the systemic inflammatory response syndrome (SIRS). A prospective study. JAMA 1995;273:117.

10. Rivers E, Nguyen B, Havstad S, Ressler J, Muzzin A, Knoblich B, Peterson E, et al. Early Goal-Directed Therapy Collaborative Group. Early goal-directed therapy in the treatment of severe sepsis and septic shock. N Engl J Med 2001;345:1368-1377

11. O’Brien JM, Ali NA, Aberegg SK, Abraham E. Sepsis. The American Journal of Medicine 2007;120:1012-1022

12. Martin GS, Mannino DM, Eaton S, Moss M. The epidemiology of sepsis in the United States from 1979 through 2000. N Engl J Med 2003;348:1546

13. Dombrovskiy VY, Martin AA, Sunderram J, Paz HL. Rapid increase in hospitalization and mortality rates for severe sepsis in the United States: A trend analysis from 1993 to 2003. Crit Care Med 2007;35:1244.

14. Esper A, Martin GS. Is severe sepsis increasing in incidence AND severity? Crit Care Med 2007; 35:1414.

15. Dombrovskiy VY, Martin AA, Sunderram J, Paz HL. Facing the challenge: decreasing case fatality rates in severe sepsis despite increasing hospitalizations. Crit Care Med 2005;33:2555.

16. Gaynes R, Edwards JR. Overview of nosocomial infections caused by gram-negative bacilli. Clin Infect Dis 2005;41:848.

17. Lever A, Mackenzie I. Sepsis: definition, epidemiology, and diagnosis. BMJ 2007;335;879-883.

18. Suarez CJ, Lolans K, Villegas MV, Quinn JP. Mechanisms of resistance to beta-lactams in some common Gram-negative bacteria causing nosocomial infections. Expert Rev Anti Infect Ther 2005;3:915.

19. Graff LR, Franklin KK, Witt L, Cohen N, Jacobs RA, Tompkins L, Guglielmo BJ. Antimicrobial therapy of gram-negative bacteremia at two university-affiliated medical centers. Am J Med 2002;112:204.

20. Dellinger RP, Levy MM, Carlet JM, Bion J, Parker MM, Jaeschke R, Reinhart K, et al. Surviving Sepsis Campaign: international guidelines for management of 
severe sepsis and septic shock: 2008. Crit Care Med. 2008;36:296-327.

21. Mackenzie I, Andrew L. Management of sepsis. BMJ 2007;335;929-932.

22. Bochud PY, Bonten M. Antimicrobial therapy for patients with severe sepsis and septic shock: an evidencebased review. Crit Care Med 2004;32:S495-S512.

23. Annane D, Sebille V, Charpentier C, Bollaert PE, François B, Korach JM, Capellier G, et al. Effect of treat- ment with low doses of hydrocortisone and fludrocortisone on mortality in patients with septic shock. JAMA 2002;288:862-871.

24. Abraham E, Laterre PF, Garg R, Levy H, Talwar D, Trzaskoma BL, Francois B, et al. Administration of Drotrecogin Alfa (Activated) in Early Stage Severe Sepsis (ADDRESS) Study Group (2005) Drotrecogin alfa (activated) for adults with severe sepsis and a low risk of death. N Engl J Med 353:1332-1341. 